\title{
Association between cognition and daily life functioning in dementia subtypes
}

Citation for published version (APA):

Bouwens, S. F. M., van Heugten, C. M., \& Verhey, F. R. J. (2009). Association between cognition and daily life functioning in dementia subtypes. International Journal of Geriatric Psychiatry, 24(7), 764-769. https://doi.org/10.1002/gps.2193

Document status and date:

Published: 01/01/2009

DOI:

10.1002/gps.2193

Document Version:

Publisher's PDF, also known as Version of record

Document license:

Taverne

Please check the document version of this publication:

- A submitted manuscript is the version of the article upon submission and before peer-review. There can be important differences between the submitted version and the official published version of record.

People interested in the research are advised to contact the author for the final version of the publication, or visit the DOI to the publisher's website.

- The final author version and the galley proof are versions of the publication after peer review.

- The final published version features the final layout of the paper including the volume, issue and page numbers.

Link to publication

\footnotetext{
General rights rights.

- You may freely distribute the URL identifying the publication in the public portal. please follow below link for the End User Agreement:

www.umlib.nl/taverne-license

Take down policy

If you believe that this document breaches copyright please contact us at:

repository@maastrichtuniversity.nl

providing details and we will investigate your claim.
}

Copyright and moral rights for the publications made accessible in the public portal are retained by the authors and/or other copyright owners and it is a condition of accessing publications that users recognise and abide by the legal requirements associated with these

- Users may download and print one copy of any publication from the public portal for the purpose of private study or research.

- You may not further distribute the material or use it for any profit-making activity or commercial gain

If the publication is distributed under the terms of Article $25 \mathrm{fa}$ of the Dutch Copyright Act, indicated by the "Taverne" license above, 


\title{
Association between cognition and daily life functioning in dementia subtypes
}

\author{
Sharon F. M. Bouwens ${ }^{1}$, Caroline M. van Heugten ${ }^{1,2}$ and Frans R. J. Verhey ${ }^{1 *}$ \\ ${ }^{1}$ School for Mental Health and Neuroscience, Department of Psychiatry and Neuropsychology, Maastricht University \\ Medical Centre, Maastricht, The Netherlands \\ ${ }^{2}$ Centre of Excellence in Rehabilitation Medicine, Utrecht, The Netherlands
}

\section{SUMMARY}

Objective To investigate the association between cognition and daily life functioning in dementia subtypes.

Methods Cross-sectional data were used from 615 patients with dementia who were referred to the Maastricht Memory Clinic of the Maastricht University Medical Centre. Pearson correlation coefficients were calculated between the MiniMental State Examination (MMSE; to measure cognitive status) and the Blessed Dementia Scale (BDS; to measure daily life functioning) for the following types of dementia: Alzheimer's Disease (AD, $n=442)$; Vascular dementia (VaD, $n=113$ ); frontotemporal dementia (FTD, $n=18$ ); Parkinson's dementia (PD, $n=21)$; and primary progressive aphasia (PPA, $n=21)$. One-way ANOVA was used to test differences in age, MMSE scores and BDS scores across dementia subtypes.

Results Scores on the MMSE showed strong correlation with BDS scores in cases of FTD $(r=-0.80)$; moderate correlation in cases of $\mathrm{AD}, \mathrm{VaD}$, and PD (range $r=-0.50-0.60$ ); while no correlation was found in PPA cases.

Conclusions The association between cognition and daily life functioning varied among dementia subtypes for AD, VaD, FTD and PD. Furthermore, the overall scores on both domains differ between dementia subtypes, indicating that different types of dementia are characterized by a specific pattern of cognitive status and daily life functioning. These findings underline the need for multidomain assessment in patients with dementia. Copyright (C) 2009 John Wiley \& Sons, Ltd.

KEY WORDS — cognition; daily life functioning; dementia; relationship; MMSE; BDS

\section{INTRODUCTION}

Dementia characterized by multidomain impairment is a common disease in old age, and it can become manifest in several forms. Alzheimer's disease (AD) is the most common dementing disorder, followed by vascular dementia (VaD) (Qiu et al., 2007). Other forms like frontotemporal dementia (FTD) (including primary progressive aphasia), and Parkinson's dementia (PD) are less frequent. The severity of dementia is traditionally measured with cognitive tests (O'Connor et al., 1989; Zhang et al., 1990; Fratiglioni et al., 1991). However, the assessment of functional impairment due to cognitive impairment is a crucial element

*Correspondence to: Prof. F. R. J. Verhey, Professor of Neuropsychiatry and Old Age Psychiatry, Maastricht University Medical Centre/Alzheimer Centre Limburg, PO Box 5800, 6202 AZ Maastricht, The Netherlands. E-mail: f.verhey@np.unimaas.nl in the diagnosis of dementia (Hendrie et al., 2006; Bouwens et al., 2008).

Various instruments are used to measure one or more domains of dementia, such as the Mini-Mental State Examination (MMSE) (Folstein et al., 1975) and the Blessed Dementia Scale (BDS) (Blessed et al., 1968); both of which are recommended by the National Institute of Neurological Diseases and Communicative Disorders and Stroke, as well as the Alzheimer's Disease and Related Disorders Association (NINCDS-ADRDA) (McKhann et al., 1984).

Several studies have found that on average there is a strong association between cognition and daily functioning in people with dementia in general (Skurla et al., 1988; Reed et al., 1989; BarbergerGateau et al., 1992). The association between cognitive status and daily life functioning in people with specific types of dementia has received less attention until now. Identifying the relation between 
cognitive status and daily life functioning for a specific dementia subtype may, however, be of diagnostic importance in practice. Furthermore, a better understanding of this association with regard to each dementia subtype is important, since it may improve insight into the different characteristics of the subtypes and may provide information about the presence of compensatory strategies for a patient's lack of abilities (i.e. daily life functioning may not be impaired if cognitive impairments are compensated adequately).

The aim of this study is to investigate the association between cognitive status and daily life functioning in people with different dementia subtypes.

\section{METHODS}

\section{Participants}

Participants were patients with dementia from the Maastricht Memory Clinic (MMC) register of the Maastricht University Medical Centre (MUMC). Patients were referred by general practitioners, neurologists, psychiatrists, and community mental health teams, or by others who were mainly internists or geriatricians (Verhey et al., 1993). The study was based on the cross-sectional data of those people who met the criteria indicating one of the following subtypes of dementia: Alzheimer's Disease (AD) (McKhann et al., 1984); Lewy body dementia (LBD) (McKeith et al., 1996); vascular dementia (VaD) (Roman et al., 1993); frontotemporal dementia (FTD) (The Lund and Manchester Groups, 1994); Parkinson's dementia (PD) (McKeith et al., 1996); or primary progressive aphasia (PPA) (The Lund and Manchester Groups, 1994). Participants included also had to have an informant who could answer questions about their condition. Furthermore, their diagnostic phase data had to be complete and their informed consent obtained. The Ethics Committee of the MUMC approved the procedure.

\section{Measures}

The Mini-Mental State Examination (MMSE) (Folstein et al., 1975) is a bedside test that measures cognitive status. The MMSE covers orientation in place and time, memory, attention, language, concentration, visuo-spatial skills, and praxis. The maximum score is 30 , with a higher score reflecting a better global cognitive status. The cut-off score is 25 (Braekhus et al., 1995).

The Blessed Dementia Scale (BDS) (Blessed et al., 1968) is a 30-min, structured interview with an informant who is close to the patient about daily functioning, cognition and behaviour in people with dementia. The scale is based on the Dementia Scale (DS) and the Information-Memory-Concentration (IMC) Test. The former tracks changes in performance of everyday instrumental activities (items 1-8) and everyday basic activities (items 9-11), as well as changes in personality, interests and drive (items 12-22). The latter assesses orientation, memory and concentration.

For this study, we used items $1-11$ of the DS, covering changes in performance of everyday instrumental and basic activities. The DS consists of items measuring both basic activities of daily life (BADL) and instrumental activities of daily life (IADL) functions (Erkinjuntti et al., 1988; Pena-Casanova et al., 2005). Changes in three BADL functions (eating, dressing and continence) are scored $0-3$ and eight items assessing changes in IADL, such as performing household tasks, coping with money or finding one's way, are scored 0 (never), 0.5 (sometimes) or 1 (nearly always). The total score ranges from 0 (independent) to 17 (dependent), with a higher score reflecting a deterioration in daily life functioning. The MMSE and the BDS were both recommended by the NINCDS-ADRDA (McKhann et al., 1984).

\section{Procedure}

Clinicians working at the Maastricht Memory Clinic (MMC) were trained in order to administer the MMSE and the BDS at the Maastricht University Medical Centre (MUMC) as part of the diagnostic phase at the MMC. Both rating scales were administered at the same visit. The caregiver was present during both assessments.

\section{Statistical analyses}

All analyses were calculated for dementia subtypes with an $n>15$. Demographic characteristics of the participants and descriptive statistics of the MMSE and the BDS were calculated. Normality tests were performed for the MMSE and the BDS. To test if dementia subtypes differed according to mean age, mean MMSE and mean BDS, One-Way ANOVAs were calculated with age, MMSE, and BDS as dependent variables and dementia subtypes as factor. Pearson correlation coefficients were calculated to examine the association between MMSE scores and BDS scores for dementia subtypes. Correlation coefficients between $0.30-0.49$ were regarded as 
low, those between $0.50-0.69$ as moderate, and those between $0.70-0.89$ as high (Hinkle et al., 1998).

We hypothesized that the association between MMSE and BDS scores differed per dementia subtype with $\mathrm{AD}$ as reference group. To facilitate interpretation of the test result, the raw scores were converted into $Z$-scores because of large differences in score range (i.e. 0-30 for the MMSE and 0-17 for the BDS) and because the scoring of both tests is reversed (i.e. higher MMSE scores signify better performance, whilst higher BDS scores signify worse performance). A repeated measures ANOVA with test score (MMSE $Z$-score, BDS Z-score) as within-subject variable and dementia subtype as between-subject variable was conducted to test this hypothesis. Statistical analyses were performed with the Statistical Package for Social Sciences (version 16.0) with an alpha level set at 0.05 for all analyses.

\section{RESULTS}

Of the 965 people with dementia in the MMC register (Verhey et al., 1993), 621 patients fulfilled the inclusion criteria of this study; 442 patients had $\mathrm{AD}$, six patients had $\mathrm{LBD}, 113$ patients had $\mathrm{VaD}$, 18 patients had FTD, 21 patients had PD, and 21 had PPA. Since the number of patients with LBD was too low to perform meaningful analyses, we did not include these for further analyses, and 615 patients remained for the present study. Table 1 shows the patients' characteristics and mean scores on the MMSE and the BDS for the total group of people with dementia $(n=615)$ and for the groups per dementia subtype separately. Level of education did not differ between dementia subtypes.

The One-way ANOVAs for mean age, MMSE and BDS for dementia subtypes all show a significant effect of dementia subtype on these mean scores
$(F=11.578, p<0.05 ; F=2.954, p<0.05 ; F=9.974$, $p<0.05$ respectively) indicating that age and MMSE and BDS scores differ with regard to dementia subtype.

Figure 1 shows the correlations between the MMSE and the BDS for the 5 different types of dementia. The Pearson correlation coefficient is -0.60 for $\mathrm{AD}$, -0.56 for $\mathrm{VaD},-0.80$ for $\mathrm{FTD},-0.50$ for $\mathrm{PD}$, and -0.00 for PPA. All correlations were significant $(p<0.00)$ except for PPA. This group showed no clear correlation.

The $Z$-scores for both the MMSE and the BDS were normally distributed. The repeated measures ANOVA for mean MMSE Z-scores and mean BDS Z-scores for dementia subtypes show a significant effect of dementia subtype on the association between the MMSE and the BDS $(F=7.123, p<0.05)$. This indicates that the association between cognitive status and daily life functioning depends on the specific dementia subtype when considering $\mathrm{AD}$ as reference group.

\section{DISCUSSION}

We investigated the association between cognitive status (MMSE) and daily life functioning (BDS) of people with different types of dementia. We found that the association between cognitive status and daily life functioning is directly related to dementia subtype.

The extent of this association differs across dementia subtypes. This supports the importance of functional as well as cognitive assessment not only to assess patient care needs but also as a possible diagnostic tool. The moderate and high correlations between the MMSE and the BDS scores are expected since the interference of cognitive functioning on daily life functioning is part of the definition of dementia.

The absence of a significant correlation in the PPA group indicates that daily life functioning is not

Table 1. Patient characteristics and mean scores on the Mini Mental State Examination and the Blessed Dementia Scale

\begin{tabular}{|c|c|c|c|c|c|}
\hline & \multirow[t]{2}{*}{$N$} & Age & \multirow{2}{*}{$\begin{array}{l}\text { Female } \\
N(\%)\end{array}$} & \multirow{2}{*}{$\frac{\text { MMSE }}{\text { Mean (SD, range) }}$} & \multirow{2}{*}{$\frac{\text { BDS }}{\text { Mean (SD, range) }}$} \\
\hline & & Mean (SD, range) & & & \\
\hline \multicolumn{6}{|c|}{ Diagnosis } \\
\hline $\mathrm{AD}$ & 442 & $72.3(8.3,49-95)$ & $266(60.2)$ & $19.2(5.7,2-29)$ & $3.5(2.4,0.5-14.0)$ \\
\hline $\mathrm{VaD}$ & 113 & $73.8(7.2,49-88)$ & $51(45.1)$ & $18.9(5.9,5-30)$ & $4.4(3.1,1.0-14.5)$ \\
\hline FTD & 18 & $63.0(9.7,49-77)$ & $10(55.6)$ & $20.6(6.9,8-29)$ & $2.9(2.4,0.5-8.5)$ \\
\hline PD & 21 & $73.9(5.3,59-82)$ & $10(47.6)$ & $15.4(4.7,2-24)$ & $5.9(3.9,1.5-15.0)$ \\
\hline PPA & 21 & $64.9(6.8,54-77)$ & $10(47.6)$ & $20.6(7.5,4-28)$ & $1.8(1.4,0.0-6.0)$ \\
\hline Total & 615 & $72.1(8.3,49-95)$ & $347(56.4)$ & $19.1(5.8,2-30)$ & $3.7(2.7,0.0-15.0)$ \\
\hline
\end{tabular}

$\mathrm{AD}=$ Alzheimer's disease $; \mathrm{VaD}=$ Vascular dementia $; \mathrm{BDS}=$ Blessed Dementia Scale $; \mathrm{FTD}=$ Frontotemporal dementia MMSE $=$ Mini Mental State Examination; PD = Parkinson's dementia; PPA = Primary progressive aphasia. 


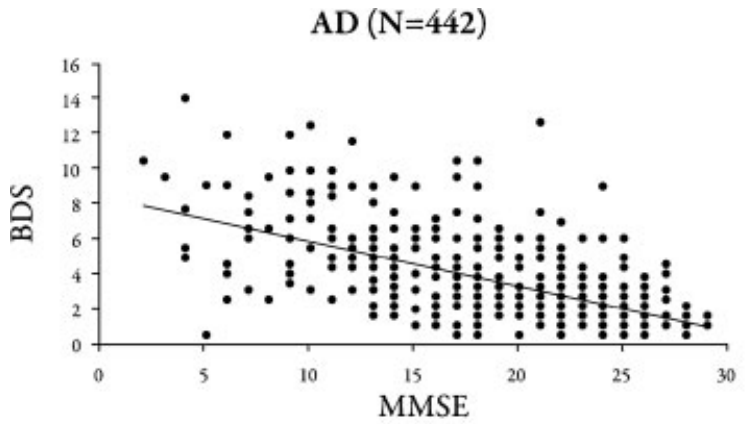

FTD $(\mathrm{N}=18)$

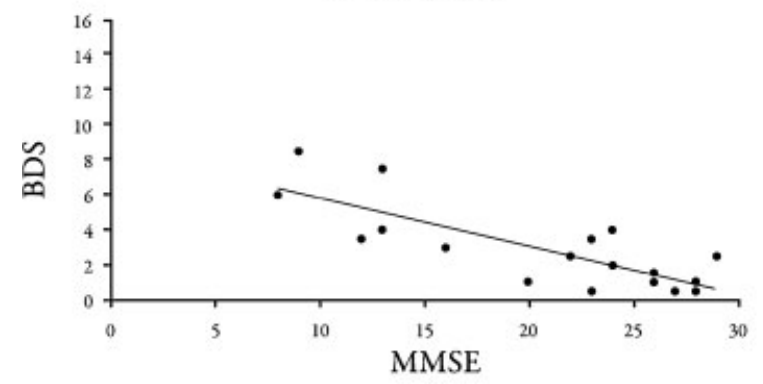

$\mathrm{VaD}(\mathrm{N}=113)$

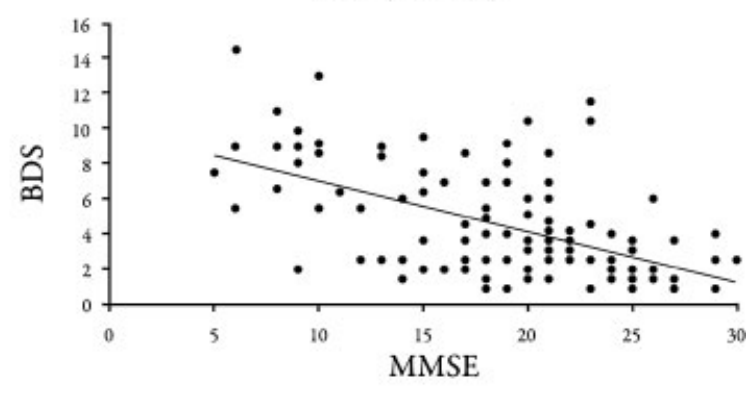

$\operatorname{PD}(\mathrm{N}=\mathbf{2 1})$

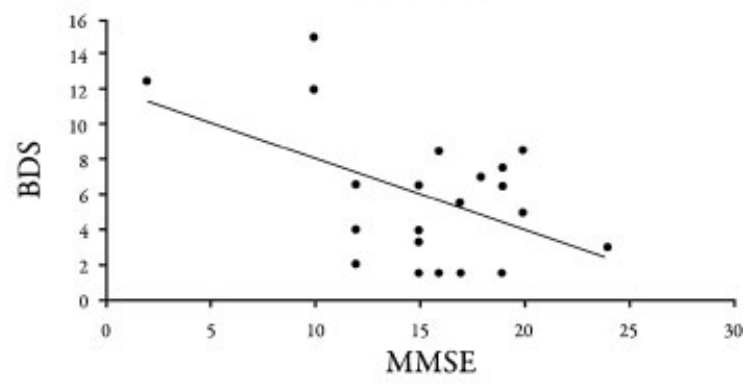

$\operatorname{PPA}(\mathrm{N}=21)$

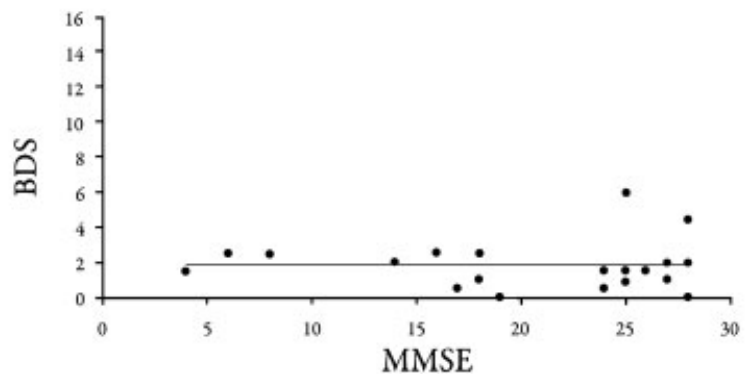

Figure 1. Association between the Mini Mental State Examination and the Blessed Dementia Scale for five dementia subtypes.

affected to the same extent as cognitive status, as indicated by the MMSE. An explanation for the absence of a significant correlation in this dementia subtype is that patients with aphasia score relatively worse on cognitive tests like the MMSE because most of the items in this test require verbal skills. However, these verbal skills do not affect the BDS because this is an informant-based rating of daily life functioning. Moreover, patients may have good compensatory abilities, which help them cope with aphasic problems in daily life. These findings are in line with Osher et al. (2008), and Mioshi et al. (2007). Clinicians should take this verbal handicap into account when testing cognitive status in people with aphasia and make better use of non-verbal cognitive tests like the Aphasia Check List (ACL) (Kalbe et al., 2005). The ACL is a 30-min test battery for the assessment of aphasic and associated cognitive disorders. It includes nonverbal screening tests for three neuropsychological domains: memory, attention, and reasoning.

Furthermore, Mioshi et al. (2007) also found that frontotemporal dementia has a negative effect on activities of daily living. Since other studies, including ours and that of Larner and Hancock (2008), have found different results, future research is necessary to study the effect of FTD on daily life functioning.

An unexpected result of our study was the comparable correlation between the MMSE and the 
BDS for AD and PD. This may be due to overlap in old criteria for PD and AD (DSM III-R and DSM IV) (American Psychiatric Association, 1995), by which the specific characteristics of each dementia subtype were not taken into account. However, there is an emerging consensus that dementia subtypes differ in clinical characteristics, which is reflected in recent proposals for specific dementing disorders (Roman et al., 1993; McKeith et al., 1996; Dubois et al., 2007).

The main strength of our study lies in the use of a large sample of clinical data. As a consequence, the dataset contained information on a heterogeneous population as it appears in everyday clinical practice, which may improve the general applicability of the results. Our data are representative according to distribution of dementia subtypes, gender in the total group and across subtypes, mean age per subtype, MMSE scores and BDS scores (Juva et al., 1997; Neary et al., 1998; Chow et al., 2006; Qiu et al., 2007; Starr and Loanie, 2007). Although our sample is in general large and representative, the number of patients with specific types of dementia, such as FTD, PD and PPA are relatively small. Therefore, these results must be interpreted with some caution.

Harwood et al. (2000) and Bouwens et al. (2008) found influences of neuropsychiatric symptoms on the cognitive status and daily life functioning of people with dementia. We did not take neuropsychiatric data into account. The association between cognition and functioning further depends on the type of IADL measures used, and whether they are based on informant-reporting, self-reporting or clinician ratings (Burton et al., 2006). Nowadays, IADL (Lawton and Brody, 1969) is recommended instead of the BDS which was chosen on the basis of the NINCDSADRDA (McKhann et al., 1984).

Discrepancies between cognitive tests and instruments for measuring activities of daily life, as is the case in our PPA group, provide important information that can guide the clinician in choosing the appropriate treatment. Since PPA, PD and FTD are relatively rare subtypes of dementia with different patterns between cognitive status and daily life functioning, clinicians must pay special attention to the possible presence of one of these three subtypes when finding relative discrepancies between cognitive status and daily life functioning.

\section{CONCLUSIONS}

Different types of dementia are characterized by different patterns of cognitive status and daily life functioning. These findings underline the need for

\section{KEY POINTS}

- The association between cognition and daily life functioning is directly related to dementia subtype.

- A multidomain approach to dementia is recommended.

- Discrepancies between cognition and daily life functioning have diagnostic relevance.

multidomain assessment in patients with dementia. Clinicians should take into account the different patterns between cognitive status and daily life functioning for each dementia subtype in order to provide appropriate care as well as adequate and accurate information. Discrepancies between cognition and daily life functioning have diagnostic relevance.

\section{CONFLICT OF INTEREST}

None known.

\section{ACKNOWLEDGEMENTS}

We would like to thank Nico Rozendaal and Wim van der Elst for their statistical advice.

\section{REFERENCES}

American Psychiatric Association. 1995. Diagnostic and Statistical Manual of Mental Disorders. American Psychiatric Association: Washington, DC.

Barberger-Gateau P, Commenges D, Gagnon M, et al. 1992. Instrumental activities of daily living as a screening tool for cognitive impairment and dementia in elderly community dwellers. $J \mathrm{Am}$ Geriatr Soc 40: 1129-1134.

Blessed G, Tomlinson BE, Roth M. 1968. The association between quantitative measures of dementia and of senile change in the cerebral grey matter of elderly subjects. Br J Psychiatry 114: 797811.

Bouwens SF, van Heugten CM, Aalten P, et al. 2008. Relationship between measures of dementia severity and observation of daily life functioning as measured with the Assessment of Motor and Process Skills (AMPS). Dement Geriatr Cogn Disord 25: 81-87.

Braekhus A, Laake K, Engedal K. 1995. A low, 'normal' score on the Mini-Mental State Examination predicts development of dementia after three years. $J$ Am Geriatr Soc 43: 656-661.

Burton CL, Strauss E, Hultsch DF, Hunter MA. 2006. Cognitive functioning and everyday problem solving in older adults. Clin Neuropsychol 20: 432-452.

Chow TW, Hynan LS, Lipton AM. 2006. MMSE scores decline at a greater rate in frontotemporal degeneration than in AD. Dement Geriatr Cogn Disord 22: 194-199. 
Dubois B, Burn D, Goetz C, et al. 2007. Diagnostic procedures for Parkinson's disease dementia: recommendations from the movement disorder society task force. Mov Disord 22: 2314-2324.

Erkinjuntti T, Hokkanen L, Sulkava R, Palo J. 1988. The blessed dementia scale as a screening test for dementia. Int J Geriatr Psychiatry 3: 267-273.

Folstein MF, Folstein SE, McHugh PR. 1975. 'Mini-Mental State'. A practical method for grading the cognitive state of patients for the clinician. J Psychiatr Res 12: 189-198.

Fratiglioni L, Grut M, Forsell Y, et al. 1991. Prevalence of Alzheimer's disease and other dementias in an elderly urban population: relationship with age, sex, and education. Neurology 41: 18861892.

Harwood DG, Barker WW, Ownby RL, Duara R. 2000. Relationship of behavioral and psychological symptoms to cognitive impairment and functional status in Alzheimer's disease. Int $J$ Geriatr Psychiatry 15: 393-400.

Hendrie HC, Lane KA, Ogunniyi A, et al. 2006. The development of a semi-structured home interview (CHIF) to directly assess function in cognitively impaired elderly people in two cultures. Int Psychogeriatr 18: 653-666.

Hinkle DE, Wiersma W, Jurs SG. 1998. Applied Statistics for the Behavioral Sciences. Houghton Mifflin Company: New York.

Juva K, Makela M, Erkinjuntti T, et al. 1997. Functional assessment scales in detecting dementia. Age Ageing 26: 393-400.

Kalbe E, Reinhold N, Brand M, et al. 2005. A new test battery to assess aphasic disturbances and associated cognitive dysfunctions-German normative data on the aphasia check list. J Clin Exp Neuropsychol 27: 779-794.

Larner AJ, Hancock P. 2008. Re: Activities of daily living in frontotemporal dementia and Alzheimer disease. Neurology 70: 658.

Lawton MP, Brody EM. 1969. Assessment of older people: selfmaintaining and instrumental activities of daily living. Gerontologist 9: 179-186.

McKeith IG, Galasko D, Kosaka K, et al. 1996. Consensus guidelines for the clinical and pathologic diagnosis of dementia with Lewy bodies (DLB): report of the consortium on DLB international workshop. Neurology 47: 1113-1124.

McKhann G, Drachman D, Folstein M, et al. 1984. Clinical diagnosis of Alzheimer's disease: report of the NINCDS-ADRDA Work Group under the auspices of Department of Health and
Human Services Task Force on Alzheimer's Disease. Neurology 34: 939-944.

Mioshi E, Kipps CM, Dawson K, et al. 2007. Activities of daily living in frontotemporal dementia and Alzheimer disease. Neurology 68: 2077-2084.

Neary D, Snowden JS, Gustafson L, et al. 1998. Frontotemporal lobar degeneration: a consensus on clinical diagnostic criteria. Neurology 51: 1546-1554.

O'Connor DW, Pollitt PA, Hyde JB, et al. 1989. The reliability and validity of the Mini-Mental State in a British community survey. J Psychiatr Res 23: 87-96.

Osher JE, Wicklund AH, Rademaker A, et al. 2008. The MiniMental State Examination in behavioral variant frontotemporal dementia and primary progressive aphasia. Am J Alzheimers Dis Other Demen 22: 468-473.

Pena-Casanova J, Monllau A, Bohm P, et al. 2005. Diagnostic value and test-retest reliability of the Blessed Dementia Rating Scale for Alzheimer's disease: data from the NORMACODEM project. Neurologia 20: 349-355.

Qiu C, De Ronchi D, Fratiglioni L. 2007. The epidemiology of the dementias: an update. Curr Opin Psychiatry 20: 380-385.

Reed BR, Jagust WJ, Seab JP. 1989. Mental status as a predictor of daily function in progressive dementia. Gerontologist 29: 804-807.

Roman GC, Tatemichi TK, Erkinjuntti T, et al. 1993. Vascular dementia: diagnostic criteria for research studies. Report of the NINDS-AIREN International Workshop. Neurology 43: 250-260.

Skurla E, Rogers JC, Sunderland T. 1988. Direct assessment of activities of daily living in Alzheimer's disease. A controlled study. J Am Geriatr Soc 36: 97-103.

Starr JM, Loanie J. 2007. The influence of pre-morbid IQ on miniMental Sate Examination score at time of dementia presentation. Int J Geriatr Psychiatry 22: 382-384.

The Lund and Manchester Groups. 1994. Clinical and neuropathological criteria for frontotemporal dementia. J Neurol Neurosurg Psychiatry 57: 416-418.

Verhey FR, Jolles J, Ponds RW, et al. 1993. Diagnosing dementia: a comparison between a monodisciplinary and a multidisciplinary approach. J Neuropsychiatry Clin Neurosci 5: 78-85.

Zhang MY, Katzman R, Salmon D, et al. 1990. The prevalence of dementia and Alzheimer's disease in Shanghai, China: impact of age, gender, and education. Ann Neurol 27: 428-437. 